glass. Any two of these form an opaque combination-that is to say, the first glass stops all the rays which could pass the second and the second stops all that pass the first. But a green and a blue glass do not form an opaque combination, but pass the green rays. If we place the red, the green, and the violet glasses in a row close to each other, with the green in the centre, place a piece of yellow glass so as to overlap the junction between the red and green glasses, and a piece of blue glass to overlap the junction between the green and violet glasses, and arrange the combination so that white light can pass through it, it will be seen that the yellow glass passes the red and green rays, and the blue glass passes the green and violet rays; and that the only effect of the yellow and blue glasses is to deepen the colours when the light passes through them.

Darrock, Falkirk, Sept. 23

loHN AITKEN

\section{Anthropology and M. Comte}

PERHAPS you will allow me to state that your report of my paper "On the Anthropology of Auguste Comte," read before the British Association at Edinburgh, is wrong in two essential particulars. First, I did not attempt to "expound the views of M. Comte according to the principles laid down by Mr. Darwin." Comte's views on man and his relation to the animal kingdom were published upwards of twenty years ago ; Mr.'Darwin's recently. Second, I did not "maintain that Auguste Comte's worship of humanity would be the great doctrine of the future." I may, and do believe this, but I made no reference to it whatever in the paper which you have so correctly mis-reported. The Positive religion was not the subject of discussion, and I limited myself to what my paper implied.

3, Osborne Ruad, Stroud Green Lane, N., Sept. 22

\section{A Plane's …. ?}

IT is perhaps answering somewhat at cross purposes, but would not the word aspect meet Mr. Wilson's requirements? In reference to those important planes of every-day life, garden walls or house fronts, its use is well established; and there would be no violence to either custom or language in applying it to geometry. J. K, LAUGHTON

[Another correspondent suggests the term "slope."-ED.]

\section{Meteorological Phenomenon}

Amongst some old memoranda I find the following, which copy verbatim :-

Old Forge, Dunmurry, Co. Antrim, Sept. I8

"Monkstown, near Dublin, about 3.ro P.M. 25th of July, $x 858$, saw, about opposite the sun, an appearance like the rainbow, but horizontal, and extending along a few degrees of the horizon. The red was above the seahorizon, and the green below. I could not make out beyond the green, but this might be because the blue was blended - with the colour of the sea. As I did not see it commence, I cannot say how long it lasted. 'It faded gradually but rapidly, without any other change in the sky that I saw. The day was alternate sunshine and heavy showers; the sun was shining at the time.

"This note has been made within half an hour after its disap. pearance."

\section{Lunar Rainbow}

A VERY perfect lunar rainbow was seen here last night. I noticed it first at 9.42 . At that time the northern portion of it only was visible, but its intensity steadily increased, and by 9.45 the arch was complete. Both at the northem and southern extremities there was a peculiar glare, extending upwards about $20^{\circ}$, the apex of the arch being remarkably clear and well-defined. The rainbow faded away as rapidly as it had been developed, and at about $9.5^{\circ}$ had entirely disappeared. At the time of the occurrence the western portion of the heavens was very clear, and the moon about $8^{\circ}$ above the horizon. 'Temperature cold, with a biting wind from W.S.W.

Hinderton, Neston, Cheshire, Sept. 23

R. B.

\section{The Corona}

MAY I suggest a method of observation which would possibly be a more delicate test than that which our own sight affords for ascertaining the outer limits of the corona?
It seems probable, from a discussion of former observations, that the polarisation of the sky is allogether changed during totality, and that instead of being radial to the sun as at other times, its plane is perpendicular, or nearly perpendicular, to the horizon. This appears at all events to be the case over a very large area about the eclipsed sun.

In passing along a parellel to the horizon through the sun's centre, we should expect to find, at some little distance from the limb, the pure atmospheric polarisation unaffected by any component due to the corona.

At such a point an observer using a Savart might therefore expect to find the bands disappear at an angle of $45^{\circ}$ to the horizon. Having carefully turned out all trace of the bands upon the centre of his field, let him now pass onward towards the sun's limb (directing his attention all the time to the centre of his field only), when he there perceives the first trace of bands. He will know that the plane of polarisation has changed. If, on going backwards, the bands disappear again, while in passing onwards they continue to increase, he will know that that change is due to a component introduced by the corona; and he will be able to estimate the distance from the moon's limb at which such a component first became visible.

I feel disposed to think that by this method he will be able to trace the corona further than he could by the unaided eye; for it will be somewhat equivalent to making the corona shine upon perfectly black back ground of sky; and much more than equivalent to accomplishing this with a Nicol only, for the Savart will detect less than one-eighth of the polarisation detectable by the Nicol.

The visible outer border of the corona is where our eye first distinguishes a difference between

$$
\text { The light of the sky }
$$
and

The light of the sky + the light of the corona,

while by this method the visible outer edge of the corona will be where we first distinguish a difference between an area of no polarisation and polarisation due to the corona.

In using a Savart with a large field, the central portion of the field might well be marked by fixing in the common focus of the telescope a plate of glass with a small circle etched upon it corresponding say to $8^{\prime}$ or $10^{\prime}$ of diameter in the field of view.

\section{A. C. RANYARD}

\section{A Rare Moth}

A FINE specimen of the rare moth Deiopeia pulchella (crimson speckled footman) was captured by $\mathrm{R}$. Beck on the Moors near Scarborough on the inth inst. Could any. of the readers of NATURE inform me whether it has ever been taken so far north before?

Oliver's Mount School, Scarborough, Sept. 22

\section{Meteorology in America}

THE writer of the article on this subject may be interested in hearing that a meteorograph, similar in some respects to that invented by Prof. Hough, was sent to the International Exhibition just closed in London. It was invented and constructed in Sweden, and one similar is said to have been performing satisfactorily for nearly three years. In the Swedish, as in the American instrument, the height of the mercury in the barometer, and the wet and dry thermometers, is felt by steel wires descending the tubes; but in the Swedish instrument the levers to which these wires are attached are acted on by very fine screws, the revolutions of which, translated by a series of wheels into the language of barometers and thermometers, are printed every quarter of an hour on an endless roll of paper. The whole apparatus is set in motion by a galvanic battery, which even winds up the clock which regulates its own action. The barometer is tapped before it is registered, but there is no correction for temperature. The price is $350 l$.

The barometer invented by Prof. Wild seems to bear some resemblance to the barograph invented by Mr. King, and now used at the Liverpool Observatory.

\section{Ruined Cities of Central America}

IN the summary of the proceedings of the late meeting of the British Association, in the issue of NATURE for August 3I, is an abstract of a paper by Captain L. Brine, R.N., On the Ruined Cities of Central America. The gallant captain is wrong in stating that the existence of these ruined cities was unknown 